\title{
Contractility of sphincter pharyngoplasty: Relevance to speech outcomes
}

\author{
Bradley A Hubbard MD ${ }^{1}$, Gale Rice PhD CCC-SLP², Arshad R Muzaffar MD ${ }^{1}$
}

\begin{abstract}
BA Hubbard, G Rice, AR Muzaffar. Contractility of sphincter pharyngoplasty: Relevance to speech outcomes. Can J Plast Surg 2013;21(1):15-18.
\end{abstract}

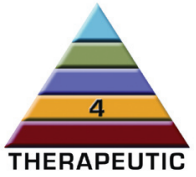

BACKGROUND: Sphincter pharyngoplasty has demonstrated timetested results as a surgical treatment for velopharyngeal incompetence (VPI). However, controversy surrounding the contractility of the transposed muscles persists. Completely unaddressed in the literature is whether the dynamism of the sphincter affects speech outcomes.

OBJECTIVE: To determine whether active sphincter contraction following sphincter pharyngoplasty influences velopharyngeal closure, nasal emission and hypernasality.

METHODS: A prospective analysis of patients with VPI after cleft palate repair undergoing sphincter pharyngoplasty by a single surgeon was performed. Video nasendoscopy and videofluoroscopy were performed preoperatively and postoperatively at three and 12 months. Eighteen consecutive patients with cleft palate with or without cleft lip and VPI were reviewed. The average age of the patients at initial evaluation was 7.3 years, with a range of three to 19 years. Dynamicity of sphincter pharyngoplasty, velar closing ratio (VCR), and lateral wall movement (LWM) were assessed by nasendoscopy and videofluoroscopy. Nasal emission and hypernasality were assessed by perceptual speech examination.

RESULTS: For longitudinal comparison, three groups were created: dynamic at three and 12 months $(n=12)$; adynamic at three months and dynamic at 12 months $(n=4)$; and adynamic at three and 12 months $(n=2)$. Perceived hypernasality scores significantly improved at three months $(\mathrm{P}=0.0001)$ and showed continued improvement at 12 months $(\mathrm{P}=0.03)$, despite no change in VCR and LWM from three to 12 months. There were no significant differences among the three groups at any time point.

DISCUSSION: Sphincter pharyngoplasty effectively treats VPI in appropriately selected patients. Although the VCR and LWM remained stable between three months and one year, four of six adynamic sphincters became dynamic. Considering all patients, hypernasality showed continued improvement from three months to one year.

CONCLUSIONS: There were no differences between dynamic and adynamic sphincters in terms of speech outcomes or the mechanical properties of velopharyngeal closure.

Key Words: Secondary speech surgery; Speech outcome; Sphincter pharyngoplasty; Velopharyngeal incompetence; Velopharyngeal insufficiency

\section{La contractilité de la pharyngoplastie du sphincter : la pertinence par rapport aux issues du discours}

HISTORIQUE : La pharyngoplastie du sphincter est un traitement chirurgical de l'incompétence vélopharyngienne (IVP) qui a fait ses preuves. Cependant, une controverse persiste à l'égard de la contractilité des muscles transposés. Les publications n'abordent pas du tout l'influence du dynamisme du sphincter sur les issues du discours.

OBJECTIF : Déterminer si la contraction active du sphincter après une pharyngoplastie du sphincter influe sur la fermeture vélopharyngienne, l'émission nasale et l'hypernasalité.

MÉTHODOLOGIE : Les chercheurs ont procédé à une analyse prospective des patients présentant une IVP après la réparation d'une fente palatine qui ont subi une pharyngoplastie du sphincter exécutée par un seul chirurgien. Ils ont procédé à une nasendoscopie vidéo et à une vidéofluoroscopie avant l'opération, puis trois et 12 mois après l'opération. Ils ont examiné 18 patients consécutifs ayant une fente palatine, accompagnée ou non d'une fente labiale, et une IVP. Les patients de trois à 19 ans avaient un âge moyen de 7,3 ans au moment de la première évaluation. Les chercheurs ont évalué le dynamisme de la pharyngoplastie du sphincter, le ratio de fermeture vélaire (RFV) et le mouvement des parois latérales (MPL) par nasendoscopie et vidéofluoroscopie. Ils ont également évalué l'émission nasale et l'hypernasalité au moyen de l'examen du discours perceptuel.

RÉSULTATS : Pour des besoins de comparaison longitudinale, les chercheurs ont créé trois groupes, soit un groupe dynamique à trois et 12 mois $(\mathrm{n}=12)$, un groupe adynamique à trois mois et dynamique à 12 mois $(\mathrm{n}=4)$ et un groupe adynamique à trois et 12 mois $(n=2)$. Leurs indices d'hypernasalité perçus s'étaient considérablement améliorés à trois mois $(\mathrm{P}=0,0001)$ et avaient continué de s'améliorer à 12 mois $(\mathrm{P}=0,03)$, malgré l'absence de changement de l'IPV et du MPL entre trois et 12 mois. On ne constatait pas de différence significative à un moment ou à un autre entre les trois groupes.

EXPOSÉ : La pharyngoplastie du sphincter traite l'IPV de manière efficace chez des patients bien sélectionnés. Même si le RFV et le MPL étaient demeurés stables entre trois mois et un an, quatre des six sphincters adynamiques sont devenus dynamiques. Chez l'ensemble des patients, l'hypernasalité s'est atténuée de manière continue entre trois mois et un an. CONCLUSIONS : On n'a constaté aucune différence entre les sphincters dynamiques et adynamiques sur les issues du discours ou les propriétés mécaniques de la fermeture vélopharyngienne.
Sphincter pharyngoplasty has shown time-tested results as a surgical $\checkmark$ treatment for velopharyngeal incompetence (VPI). On its introduction by Hynes in 1950 (1), it was believed that with its use, velopharyngeal closure would be augmented not only by narrowing the lateral extents of the velopharyngeal port, but would be further improved by the contractile properties of the muscles (originally the salpingopharyngeus, later including the palatopharyngeus). Since then, this notion has come under scrutiny.

In 1998, Witt et al (2) reviewed pre- and postoperative videofluoroscopies to account for minimal and maximal excursion of the sphincter in the basal view. In this study, the authors concluded that sphincter pharyngoplasty appeared to be dynamic after the majority of their surgeries. In a follow-up study the same year, Witt et al (3) questioned whether the dynamism of the sphincter was due to pre-existing posterior pharyngeal wall motion. They performed lateral videofluoroscopic evaluations preoperatively and postoperatively for 20 patients who underwent sphincter pharyngoplasty and concluded that after comparing preoperative and postoperative parameters, the surgery did not significantly affect posterior pharyngeal wall motion and that preexisting posterior pharyngeal wall motion was not the cause of sphincter dynamism.

Georgantopoulou et al (4) used tracings of a velopharyngeal port made from pre- and postoperative videofluoroscopies to measure velar elevation associated with port closure in patients who had undergone

${ }^{1}$ Division of Plastic Surgery, University of Missouri; ${ }^{2}$ Fontbonne University, St Louis, Missouri, USA

Correspondence: Dr Arshad R Muzaffar, Division of Plastic Surgery, University of Missouri, One Hospital Drive, Columbia, Missouri 65212,

USA. Telephone 573-882-2275, fax 573-884-4788, e-mail muzaffara@missouri.edu 


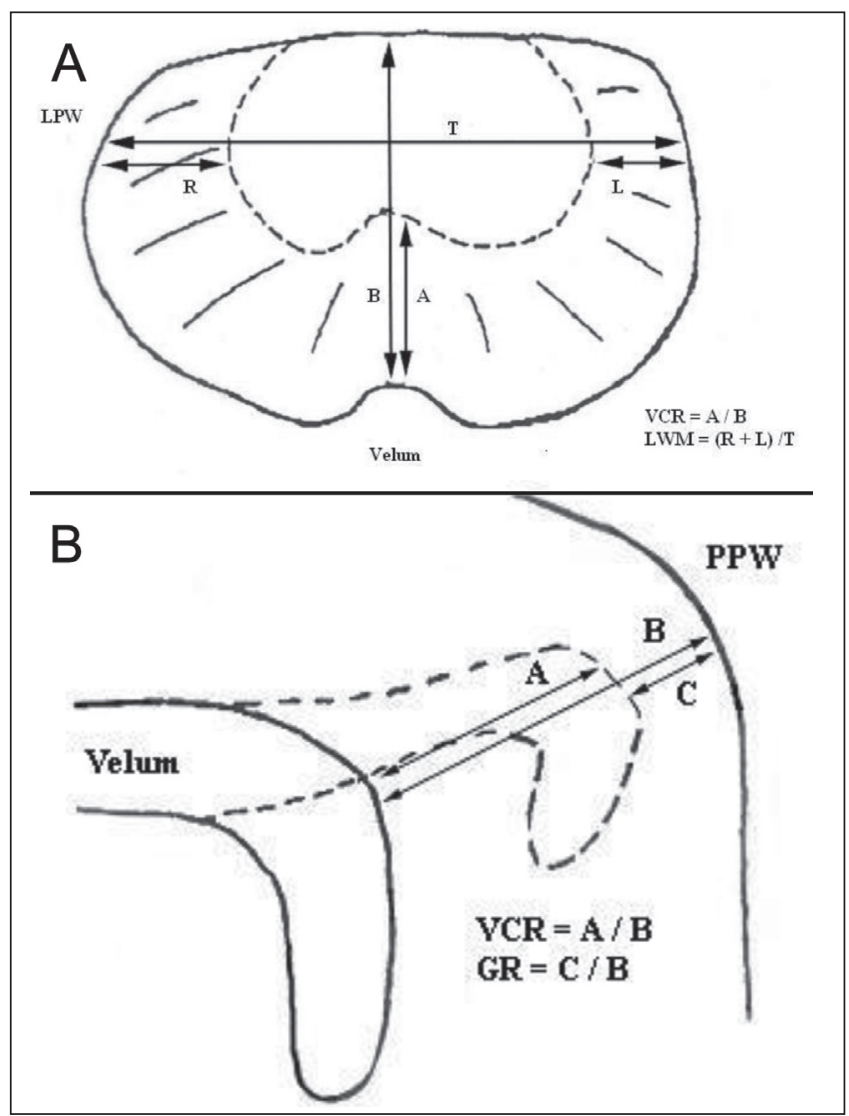

Figure 1) Schematic drawing of the nasopharynx. Measurements for velar closing ratio (VCR), lateral wall movement (LWM) and gap ratio (GR) are diagrammed. A Nasendoscopic view. B Lateral videofloroscopic view. A Velar excursion; B Distance from velum to posterior pharynx at rest; L Left; LPW Lateral phayngeal wall; PPW Posterior pharyngeal wall; R Right

sphincter pharyngoplasty. They concluded that there was a significant increase in postoperative palatal movement. However, they also concluded that there was no correlation between movement increase and improvement in speech.

In 1999 (5) and 2006 (6), Ysunza et al studied the contractile properties of the transposed palatopharyngeus muscles. Under videofluoroscopy, the veloparyngeal port was studied for signs of improved dynamic closure. At the same time, an electromyographic study of the superior pharyngeal constrictor, the levator veli palatini and the palatopharyngeus muscles themselves was obtained. While $92 \%$ of the study sample demonstrated complete velopharyngeal closure after the operation, none of the patients showed electromyographic activity (ie, contraction) of the transposed palatopharyngeus muscles during attempted velar closing. Confounding interpretation of these results, however, was the fact that patients were not used as their own controls in pre- and postoperative comparison. Neither Witt et al $(2,3)$ nor Ysunza et al $(5,6)$ compared speech outcomes in patients with dynamic sphincters versus adynamic sphincters in these studies.

The studies discussed above highlight the controversy surrounding the contractility of the transposed muscles. Completely unaddressed is whether the dynamism of the sphincter affects speech outcomes. In the present study, we investigated whether resolution of nasal emission and hypernasality differs following sphincter pharyngoplasty among patients with dynamic and adynamic sphincters.

\section{METHODS}

A prospective study of 18 consecutive patients undergoing sphincter pharyngoplasty for VPI was performed. Institutional review board approval was obtained. All patients met the following inclusion criteria: velopharyngeal insufficiency; subjects previously underwent palatoplasty for a cleft of the secondary palate; and subjects were already followed in the craniofacial anomalies clinic. Patients who had velopharyngeal insufficiency without a cleft of the secondary palate, patients with palatal fistula and patients with previous pharyngeal surgery were excluded. In addition, patients with a syndrome, hearing loss or mental retardation were excluded.

Of the 18 patients enrolled in the study, one had a history of a submucous cleft palate, six had cleft palate, three had bilateral cleft lip and palate, and eight had unilateral cleft lip and palate. All patients underwent primary palate repairs: six underwent two-flap palatoplasty, four underwent a Von Langenbeck-style repair and eight were unknown because repairs were performed at outside facilities. Additionally, seven patients had a history of secondary Furlow palatoplasty for palatal lengthening.

A standardized protocol for speech evaluation, nasendoscopy and videofluoroscopy was used. Pre- and postoperative evaluations of a single speech and language pathologist were reviewed, as were the outcomes of pre- and postoperative nasendoscopy and multiview videofluoroscopy on each of these 18 patients. Nasendoscopy and video fluoroscopy were performed by the same surgeon (ARM) in conjunction with a single speech and language pathologist (GR). For all measurements, the patients' best performances were used to determine their ratings as described below. Agreement between the speech and language pathologist and surgeon was $100 \%$ for these ratings. Surgical complications were defined as any occurrence that required a return to the operating room in the early postoperative period (14 days) or revision of the procedure at any time.

Perceptual speech assessment included rating of nasal emission, hypernasality, cul-de-sac resonance, articulation, general intelligibility and presence of facial grimacing. Contexts used for assessment included counting, phonetically balanced sentences and conversation. Nasal emission was delineated according to phoneme. Hypernasality was rated on a four-point scale with respect to both severity and consistency. Intelligibility was rated on a three-point scale.

The measurements obtained through nasendoscopy and videofluoroscopy were based on normalized diagrams (Figures 1A and 1B). These measurements were derived from the recommendations of the International Working Group (7). On nasendoscopy, velar closing ratio (VCR) measured the maximal velar excursion as a percentage or ratio of the distance from the resting velum to the posterior pharyngeal wall. Lateral wall movement (LWM) was measured on a scale of 0.0 to 0.5 for each lateral wall, with 0.5 denoting movement to the midline. The LWM was recorded as total LWM, whereby contact in the midline would be denoted by a combined score of 1.0.

On videofluoroscopy, velar excursion was studied on lateral views. VCR was measured as described above. LWM was noted on basal views and measured as described above for nasendoscopic examinations.

The sphincter pharyngoplasties were performed in a standardized fashion, and all were performed or supervised directly by a single surgeon (ARM) using previously described methods $(8,9)$. The amount of flap overlap was individualized for each patient based on the preoperative nasendoscopy and videofluoroscopy examinations. Specifically, the greater the LWM, the less the degree of overlap. Thus, for example, if $\mathrm{LWM}=0$, then the flaps were overlapped $100 \%$, whereas if $\mathrm{LWM}=0.5$, the flaps were overlapped $50 \%$. When LWM was asymmetrical, the degree of flap overlap was also adjusted asymmetrically, with greater movement of the flap on the side with less LWM toward the opposite lateral wall.

Patients received no speech therapy for three months postoperatively. At that time, measurements taken preoperatively were repeated, and it was determined whether the sphincter was dynamic or adynamic by direct visualization on nasendoscopy and videofluoroscopy. Active sphincter contraction was defined as concentric velar closure not present on preoperative examination. Care was taken to avoid confounding posterior or LWM. Speech therapy programs were 
TABLE 1

Measurements of valve mechanics and perceptual speech scores at preoperative (pre) state and following surgery (three months and 12 months)

\begin{tabular}{|c|c|c|c|c|c|c|c|}
\hline Variable & Changes defined by & All groups & $\mathrm{P*}$ & Dynamic-dynamic & Adynamic-dynamic & Adynamic-adynamic & $\mathbf{P}^{\dagger}$ \\
\hline \multirow[t]{3}{*}{ Velar closing ratio } & 3 months - pre & & & $0.17 \pm 0.32(n=11)$ & $0.13 \pm 0.09(n=4)$ & $0.05 \pm 0.42(n=2)$ & 0.51 \\
\hline & 12 months - pre & & & $0.23 \pm 0.30(n=10)$ & $0.15 \pm 0.11(n=4)$ & $-0.05 \pm 0.64(n=2)$ & 0.77 \\
\hline & 12 months -3 months & & & $0.03 \pm 0.05(n=9)$ & $0.03 \pm 0.05(n=4)$ & $-0.10 \pm 0.21 \quad(n=2)$ & 0.85 \\
\hline \multirow{3}{*}{$\begin{array}{l}\text { Lateral wall } \\
\text { movement }\end{array}$} & 3 months - pre & & & $0.23 \pm 0.2(n=8)$ & $0.24 \pm 0.16(n=4)$ & $-0.05 \pm 0.07(n=2)$ & 0.73 \\
\hline & 12 months - pre & & & $0.17 \pm 0.26(n=9)$ & $-0.05 \pm 0.13(n=4)$ & $0.15 \pm 0.21 \quad(n=2)$ & 0.10 \\
\hline & 12 months -3 months & & & $-0.12 \pm 0.31(n=8)$ & $-0.29 \pm 0.22(n=4)$ & $0.20 \pm 0.14(n=2)$ & 0.15 \\
\hline \multirow[t]{3}{*}{ Hypernasality } & 3 months - pre & $-1.24 \pm 0.83(n=17)$ & 0.0001 & $-1.27 \pm 1.01(n=11)$ & $-1.25 \pm 0.5(n=4)$ & $-1.0 \pm 0.00(n=2)$ & 0.95 \\
\hline & 12 months - pre & $-1.75 \pm 0.86(n=16)$ & $<0.0001$ & $-1.80 \pm 0.79(n=10)$ & $-1.50 \pm 1.29(n=4)$ & $-2.0 \pm 0.00(n=2)$ & 0.65 \\
\hline & 12 months -3 months & $-0.60 \pm 0.83(n=15)$ & 0.03 & $-0.67 \pm 0.71(n=9)$ & $-0.25 \pm 1.26(n=4)$ & $-1 \pm 0.00(n=2)$ & 0.36 \\
\hline \multirow[t]{3}{*}{ Nasal emission ${ }^{\star \dagger}$} & 3 months - pre & & & $-0.36 \pm 0.50(n=12)$ & $-1.00 \pm 0.00(n=4)$ & $-0.50 \pm 0.71(n=2)$ & 0.20 \\
\hline & 12 months - pre & & & $-0.33 \pm 0.50(n=4)$ & $-0.75 \pm 0.50(n=4)$ & $-0.5 \pm 0.71 \quad(n=4)$ & 0.40 \\
\hline & 12 months -3 months & & & $-0.13 \pm 0.64(n=2)$ & $-0.25 \pm 0.50(n=4)$ & $0.00 \pm 0.00(n=2)$ & 0.50 \\
\hline
\end{tabular}

Data presented as mean $\pm S D$ unless otherwise indicated. Values shown represent the difference between the time points indicated. *Wilcoxon signed rank test; ${ }^{\dagger}$ Kruskall-Wallis test. The velar closing ratio was taken from nasendoscopy studies and lateral wall movement from videofluoroscopy studies. The variable nasal emission had binary responses; present or absent. The response 'present" was coded as ' 1 ' and 'absent' was coded as ' 0 '. Thus, the mean nasal emission represents the proportion of changes from 'Yes' to 'No' for the negative mean, and from 'No' to 'Yes' for the positive mean

then designed for patients in need. At 12 months postoperatively, the measurements were repeated.

To follow these patients longitudinally, three groups were created: dynamic at both time points; adynamic at three months and dynamic at 12 months; and adynamic at three months and 12 months. Three patients had incomplete postoperative follow-up. One patient was not evaluated at three months, but was found to be dynamic at 12 months and was grouped with patients who were dynamic at both time points. Two patients were not evaluated at the 12 -month time point. They were placed in the group that was dynamic at both time points. The placement of these patients into their respective groups was based on the assumption that no other patient regressed from dynamic to adymanic during this time period. The data analysis, in part, accounted for these assumptions by comparing the groups assuming the change in value from two time points. Therefore, any patient without data from both time points was excluded from that test.

Descriptive statistics, such as mean and SD, were computed for all change scores. Because the scale of the data was ordinal, nonparametric testing was applied using the change score between any two given time points of three as a dependent and the group assignment as an independent variable. For between-group comparisons, the KruskallWallis test was used, while the signed rank test was used to test changes after combining the three groups. SAS version 9.2 (SAS Institute Inc, USA) was used for all data analyses.

\section{RESULTS}

Eighteen consecutive patients who underwent sphincter pharyngoplasty were identified. The average age of the patients at preoperative evaluation was 7.3 years, with a range of three to 19 years. No early or late postoperative complications occurred.

Preoperatively, the patients had an average VCR of 0.78 by nasendoscopy and 0.91 by videofluoroscopy. LWM was 0.2 and 0.34 , respectively. Perceptual speech examination revealed an average hypernasality score of $1.94(0=$ none, $3=$ severe $)$ and nasal emission was present in 12 of 18 patients.

Three months following surgery, the average VCR improved to 0.94 by nasendoscopy and 0.97 by videofluoroscopy. The average LWM improved to 0.26 and 0.55 , respectively. Perceptual speech improved both in terms of hypernasality and nasal emission. The average hypernasality score improved to $0.76(\mathrm{P}=0.0001)$ and three of 17 had nasal emission.

One year following surgery, the average VCR remained stable at 0.95 by nasendoscopy and 0.98 by videofluoroscopy. Average
LWM trended lower, but there was no statistically significant change ( 0.14 and 0.50 , respectively). Perceptual speech continued to improve from three months to 12 months. The hypernasality score showed statistically significant improvement, with an average score of $0.2(\mathrm{P}=0.03)$. The number of patients with nasal emission remained stable (three of 16).

Active sphincter contraction was defined as concentric velar closure absent at the preoperative examination. None of the patients had a Passavant's ridge or significant posterior wall motion at their preoperative evaluation. Three months following surgery, 12 of 18 patients $(66 \%)$ were found to have dynamic sphincters. At one year, 14 of 16 patients $(82 \%)$ were found to have dynamic sphincters. None of the patients with dynamic sphincters at three months were found to be adynamic at one year, although two patients were not evaluated at 12 months. Four of the six previously adynamic sphincters became dynamic during this time period. To follow these patients longitudinally, three groups were created: dynamic at both time points; adynamic at three months and dynamic at 12 months; and adynamic at three months and 12 months. No statistical difference was found among the three groups at the preoperative, three-month or 12-month postoperative examinations in terms of the mechanical properties of the valve or speech outcomes (Table 1).

\section{DISCUSSION}

Although sphincter pharyngoplasty has been used as a treatment for VPI for almost 60 years, the issue of whether the surgically constructed sphincter is dynamic remains unresolved. Furthermore, the specific issue of whether there is a relationship between the contractility of the sphincter and the ultimate speech outcome has not been directly examined in the literature.

In the present study, we sought to determine whether improvement of velopharyngeal closure, nasal emission and hypernasality differs following sphincter pharyngoplasty among patients with dynamic and adynamic sphincters. For the purposes of the present study, we chose not to use the terms 'VPI' or 'velopharyngeal insufficiency'. Instead, we isolated VPI into its two components: 'velopharyngeal closure', referring to mechanical properties of the velopharyngeal valve, and the perceptual characteristics of the patient's speech. As Jackson and Silverton (8) noted, “... speech change did not always correlate accurately with the $\mathrm{x}$-ray findings, or with direct or indirect visualization of velopharyngeal closure".

Considering the mechanical properties of velopharyngeal closure, VCR and LWM both increased three months following the surgery. At 
12 months following surgery, no further improvement was apparent. Sixty-six per cent of our patients were determined to have dynamic sphincters at three months and $82 \%$ at 12 months. The change represents four of the six previously adynamic sphincters becoming dynamic. We found no statistically significant differences between dynamic and adynamic sphincters in terms of VCR or LWM at any time points: preoperative, three months or 12 months postoperatively. The comparison between dynamic and adynamic sphincters was limited at the 12 -month time point due to the small sample size of the adynamic group $(\mathrm{n}=2)$.

Considering the characteristics of perceptual speech, hypernasality and nasal emission, both improved significantly at three months postoperatively. While the percentage of patients with nasal emission remained stable at one year, hypernasality continued to improve at the one-year visit $(\mathrm{P}=0.03)$. Again, no differences were found between dynamic and adynamic groups at any time point.

The continued improvement in hypernasality between three and 12 months was a curious finding because it is not accounted for by changes in the mechanical properties of the valve. The etiology is most likely related to spontaneous improvement in velopharyngeal coordination or trained improvement through speech therapy or both. A control group of patients with VPI who had no surgery would have been useful to make this conclusion. No previous study has shown an improvement in hypernasality over time because few groups have presented results with multiple postoperative time points. The VPI Surgical Trial Group compared sphincter pharyngoplasty and pharyngeal flap (10). Using the end point of hypernasal resonance, the sphincter pharyngoplasty group was found to be inferior at the threemonth time point $(\mathrm{P}<0.01)$ but equivalent at one year. Further review of their data shows the etiology of this change was continued improvement in the sphincter pharyngoplasty group and no change in the flap group.

The published surgical success rates of sphincter pharyngoplasty range from $68 \%$ to $90 \%$. This wide range is accounted for, in part, by nearly every study using different primary outcome measures - namely, complete velopharyngeal valve closure, nasometry readings, surgical revision rates and speech improvement. The most important patientcentred outcome is perceived speech; however, objectively measured

\section{REFERENCES}

1. Hynes W. Pharyngoplasty by muscle transplantation. Br J Plast Surg 1950;3:128-35.

2. Witt PD, Marsh JL, Arlis H, Grames LM, Ellis RA, Pilgram TK. Quantification of dynamic velopharyngeal port excursion following sphincter pharyngoplasty. Plast Reconstr Surg 1998;101:1205-11.

3. Witt PD, Myckatyn T, Marsh JL, Grames LM, Pilgram TK. Does preexisting posterior pharyngeal wall motion drive the dynamism of sphincter pharyngoplasty? Plast Reconstr Surg 1998;101:1457-62.

4. Georgantopoulou AA, Thatte MR, Razzell RE, Watson AC. The effect of sphincter pharyngoplasty on the range of velar movement. Br J Plast Surg 1996;49:358-62.

5. Ysunza A, Pamplona MC, Molina F, Chacon E, Collado M. Velopharyngeal motion after sphincter pharyngoplasty: A videonasopharyngoscopic and electromyographic study. Plast Reconstr Surg 1999;104:905-10.

6. Ysunza A, Pamplona MC. Velopharyngeal function after two different types of pharyngoplasty. Int J Pediatr Otorhinolaryngol 2006;70:1031-7. parameters lend themselves more readily to outcomes research. The mechanical properties of the valve (eg, complete velopharyngeal closure) have been used in the past as an objective outcome measure but, as we have shown in our patients, a good correlation does not always exist. From three to 12 months, the mechanical properties of the valve were unchanged while hypernasality scores showed statistically significant continued improvement.

Given our findings and those of other authors, such as Jackson and Silverton (8), we contend that both the mechanical properties of the valve and perceptual speech assessment should be reported in studies on the outcome of sphincter pharyngoplasty and other procedures for the treatment of VPI. Perceived speech represents a complex interplay of many different factors: while measurements of velopharyngeal closure are helpful to surgeons trying to asses the effectiveness of their surgical technique, perceived speech is the outcome that is most relevant to the patient. Thankfully, the significance of patient-based outcome measures is now being recognized more broadly in plastic surgery (11).

The presence of spontaneous contraction of the transposed palatopharyngeous muscles after sphincter pharyngoplasty has been highly disputed in the literature as highlighted previously. We have demonstrated that contractility exists in some patients and may not be apparent until one year following surgery. This finding aside, contractility of these muscles did not impact speech outcomes in our patients.

\section{CONCLUSION}

Sphincter pharyngoplasty effectively treats VPI in appropriately selected patients. Although the mechanical properties of velopharyngeal closure were improved at three months postoperatively, no further improvement was measured at one year; however, speech outcomes showed continued improvement at one year. For this reason, we would recommend waiting at least one year following surgery before any further surgical intervention for hypernasal speech or nasal emission.

Our group found that $66 \%$ of sphincter pharyngoplasties were dynamic at three months and $82 \%$ at one year. There was no difference between dynamic sphincters and adynamic sphincters at any time point in terms of speech outcomes, LWM or VCRs.

7. Golding-Kushner KJ, Argamaso RV, Cotton RT, et al. Standardization for the reporting of nasopharyngoscopy and multiview videofluoroscopy: A report from an International Working Group. Cleft Palate J 1990;27:337-47.

8. Jackson IT, Silverton JS. The sphincter pharyngoplasty as a secondary procedure in cleft palates. Plast Reconstr Surg $1977 ; 59: 518-24$

9. Kawamoto HK Jr. Pharyngoplasty revisited and revised. Oper Tech Plast Reconstr Surg 1995;2:239-44.

10. Abyholm F, D'Antonio L, Davidson Ward SL, et al. Pharyngeal flap and sphincterplasty for velopharyngeal insufficiency have equal outcome at 1 year postoperatively: Results of a randomized trial. Cleft Palate Craniofac J 2005;42:501-11.

11. Wong KWY, Goodacre T, Forrest CR, et al. Developing a PatientReported Outcome Measure for Cleft Lip and Palate (CLEFT-Q): Item generation. Presented at the American Association of Plastic Surgeons 91st Annual Meeting and Symposium. San Francisco, April 16, 2012. 